\title{
Circulação, percursos e visuais em espaços de arte e cultura concebidos por Rem Koolhaas
}

\author{
Ana Tagliari ${ }^{1}$ \\ Wilson Florio ${ }^{2}$ \\ DOI 10.20396/eha.vil4.3450
}

\section{Introdução}

O presente artigo destaca a importância dos elementos de circulação nos edifícios de arte e cultura projetados pelo arquiteto Rem Koolhaas (OMA). Foram identificadas estratégias do arquiteto na definição e organização de caminhos e percursos no interior dos edifícios, de modo a aguçar percepção, destacar visuais e direcionar o olhar dos usuários pelo espaço. Durante a pesquisa foram analisados e visitados 7 edifícios. Neste artigo apresentamos 3 projetos, e que envolvem diferentes expressões de arte e cultura: Kunsthal (1992), Prada Epicenter (2000) e Stedlijck BASE (2017). A experiência de vivenciar os espaços concebidos por Koolhaas é como um labirinto dinâmico, com visuais inesperadas ao longo do percurso, que exige um observador ativo e atento, como uma metáfora do mundo contemporâneo.

A partir dos conceitos e premissas estabelecidos pelo próprio arquiteto, e da análise de seus projetos, foram identificadas suas estratégias para direcionar caminhos, percursos, percepção, visuais e olhares dos usuários pelo espaço. Por meio da leitura dos textos do próprio arquiteto, notouse que Koolhaas explora diferentes modos de representação para apresentar suas ideias. Por este motivo, optou-se por análises gráficas e sequência de fotos, pois vem ao encontro da essência desta pesquisa: movimento, circulação e o direcionamento de olhares e visuais pelos espaços.

Durante a pesquisa pode-se notar que as visuais definidas pelos percursos planejados pelo arquiteto são fundamentais para que o usuário perceba o espaço. Assim, a partir da investigação conceitual e funcional do percurso e da circulação das obras, foram estabelecidos os seguintes procedimentos metodológicos: i) levantamentos de textos e de imagens a partir de fontes primárias; ii) relação entre conceitos e prática projetual estabelecidos pelo arquiteto; iii) visitas às obras selecionadas; iv) desenhos de observação; v) análise gráfica; vi) reflexão e síntese. 
A motivação da presente pesquisa reside no enfrentamento das dificuldades dos estudantes para definir circulações nos edifícios. Assim, a pesquisa surgiu da necessidade e do interesse de se criar um material de apoio, envolvendo o estudo dos elementos arquitetônicos e sistemas de circulação.

Movimento pelo espaço: circulação, percurso e visuais

A investigação de um projeto a partir do olhar sobre o sistema de circulação pode revelar aspectos conceituais e estratégias projetuais. A boa arquitetura tem o sistema de circulação bem resolvido, tanto na aproximação ao edifício, como na organização dos seus acessos e percursos internos.

Analisar a circulação de um projeto de arquitetura não nos oferece apenas informações sobre soluções funcionais e objetivas, mas também sobre questões conceituais, perceptivas e artísticas, que atuam diretamente no modo de olhar do usuário.

O sistema de circulação é composto por diversos tipos de elementos. É possível analisar a circulação de um projeto a partir de critérios claros e objetivos. Para tanto é necessário estabelecer uma base conceitual para a correta análise.

Há quatro modos de organização do sistema de circulação: 1) o modelo clássico, com espaços fragmentados e conectados sequencialmente entre si; 2) o modelo conceitual moderno, que prevê um espaço amplo e desobstruído, onde o percurso pelo espaço faz com que o usuário tenha a compreensão do todo; 3) o modelo conceitual trazido pela pós-modernidade, onde o usuário é impelido a descoberta paulatina do espaço, com descobertas graduais durante o percurso; e, por fim; 4) o modelo contemporâneo, marcado pela pluralidade e pela diversidade. Portanto, identificamos uma mescla entre conceitos modernos e pós-modernos no que diz respeito à circulação, unindo a fluidez e domínio do espaço da promenade com as descobertas quadro a quadro do período pósmoderno3.

Na contemporaneidade Rem Koolhaas é o arquiteto que expressa indagações instigantes sobre circulação, seja pelos seus escritos, seja pela concretização deles em seus projetos. Para o arquiteto, tanto o elevador, que fragmenta e interfere na percepção e relação dos espaços, como a escada rolante, que conduz a um movimento contínuo e lento pelo espaço, são elementos de especulação 

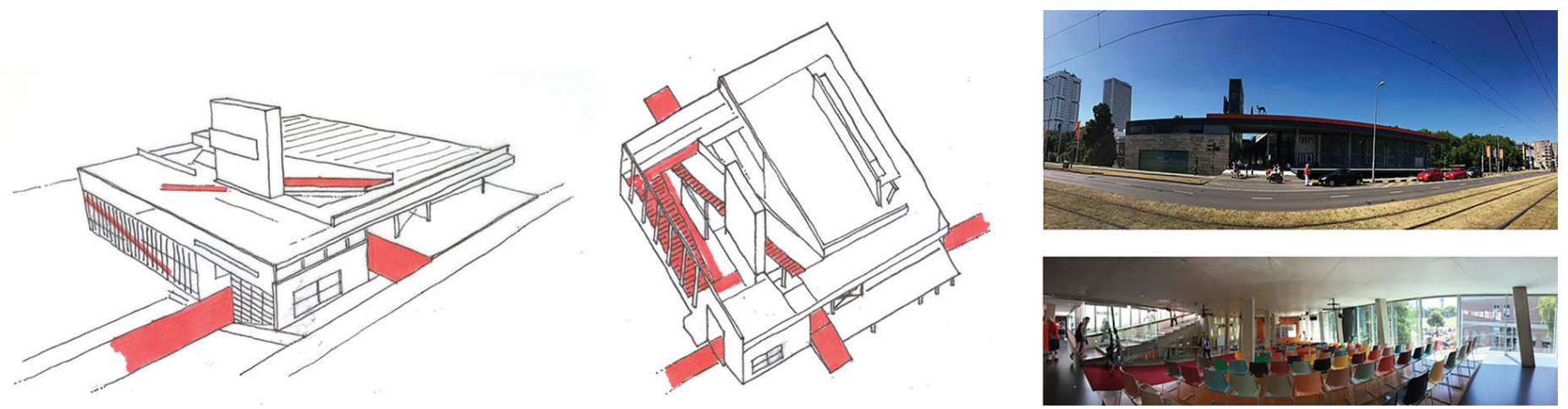

[Figura 1] Rem Koolhaas. Kunsthau. 1992. Fonte: Desenhos e Fotos dos Autores, 2018
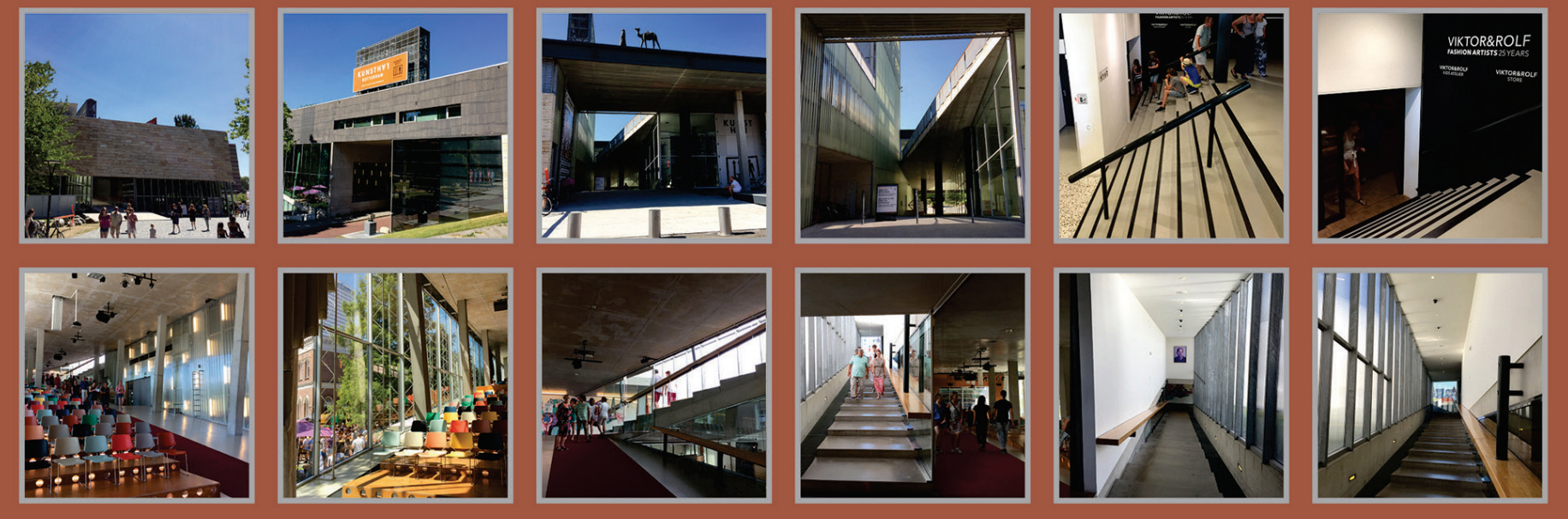

[Figura 2] Rem Koolhaas. Kunsthau. 1992. Fonte: Fotos dos Autores, 2018

[Figura 3] Rem Koolhaas. Prada Epicenter NY. 2000. Fonte: Desenhos e fotos dos autores, 2009 

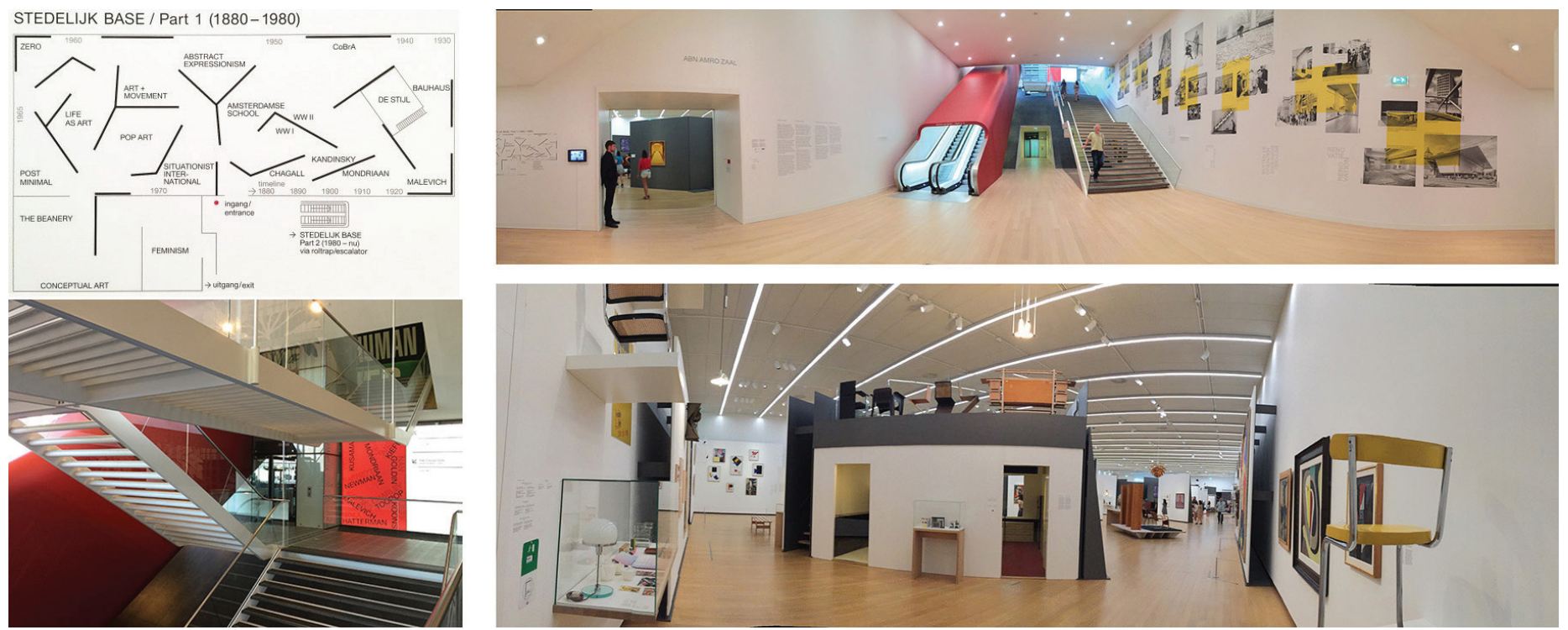

[Figura 4] Rem Koolhaas. Stedlijck BASE. 2017. Fonte: Fotos dos Autores, 2018.
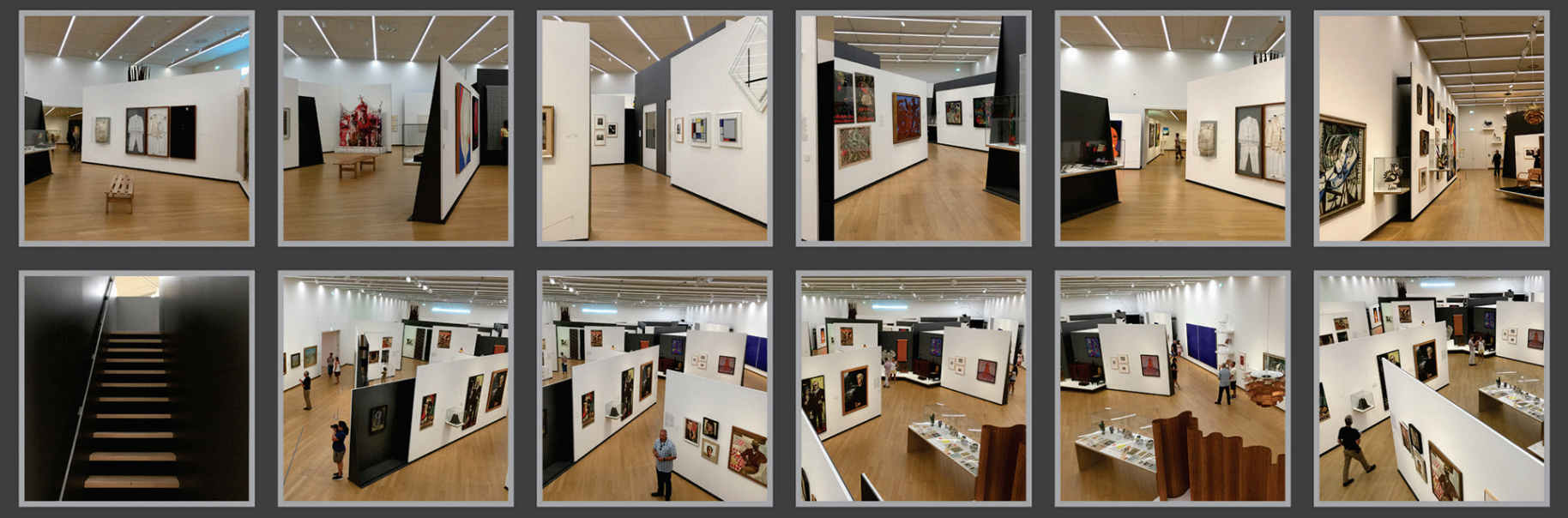

[Figura 5] Rem Koolhaas. Stedlijck BASE. 2017. Fonte: Fotos dos Autores, 2018 
conceitual, na direta relação entre a vida e a cidade contemporânea.

O arquiteto escreveu livros, onde apresenta, de forma profunda, seus conceitos, tais como, espaço-lixo, cultura da congestão, lobotomia, cidade genérica e bigness.

Por outro lado, Koolhaas afirma que, quando adolescente, costumava visitar o Museu Stedelijk em Amsterdã. O arquiteto destaca a exposição ocorrida em 1962, chamada Dylaby, que tinha como conceito a ideia de que o público deveria participar e interagir mais com o espaço e a obra de arte. Segundo o arquiteto "Dylaby-a dynamic labyrint agora também seria um título profético. Todas essas exposições me permitiram ser mais moderno do que os meus pais... portanto de alguma forma fui doutrinado por elas"'. Como será visto adiante, tais ideias repercutem na conceituação de sua obra.

Kunsthal (Roterdã, 1987-92)

O Kunsthal abriga em $8000 \mathrm{~m}^{2}$ espaços de exposição, um auditório, um restaurante, inseridos num edifício localizado no Museum Park, importante parque cultural de Roterdã. No livro S,M,L,XL (1995) este edifício é apresentado como uma experiência multissensorial.

Alexandro Zaera ${ }^{5}$ qualifica o Kunsthal como um elemento conector:

Between a high density traffic thoroughfare and the zone bounded to the South by the Museum Park - an important connecting element between objects and highly diverse buildings - the new construction is confronted with a dual situation.

O programa previa três amplos espaços para exposições, um auditório que deveria ser planejado de modo a ser usado independente ou em conjunto com as exposições, e um restaurante com acesso independente. Os pavimentos são interligados por rampas, escadas e elevadores.

O edifício foi concebido com dois eixos se cruzando: um norte-sul e outro leste -oeste, formando assim um quadrado dividido em quatro partes independentes, mas que possuem uma circulação que as tornam parte de um percurso pré-concebido, metaforicamente como uma espiral contínua.

O cruzamento de duas rampas define o acesso principal do edifício, num ponto de convergência de fluxos e encontros. Uma rampa é pública, localizada perpendicular à rua, que conecta a cota mais alta do terreno com a mais baixa, chegando ao Museum Park na face norte. O usuário 
ao cruzar esta rampa pública, está conectado visualmente aos ambientes internos do museu, que possui os fechamentos em vidro. A segunda rampa, interna, e integrada ao auditório, está localizada paralela a rua, e configura a cobertura do restaurante que está localizado no piso inferior. Neste ambiente o usuário domina o ambiente com o olhar, inclusive o parque, pois o auditório tem seu perímetro todo em vidro.

De fato, como bem observou o arquiteto Rafael Moneo ${ }^{6}$, o edifício promove o movimento: "(...) the prism is transformed by means of a series of slanted planes that help consolidate the program while fostering movement".

A rampa, os pilares inclinados e o movimento conferem dinamismo ao auditório, enquanto a iluminação natural, que entra pelo perímetro de vidro, proporciona boas visuais das atividades que ocorrem no parque. Portanto, o usuário é impelido a direcionar seu olhar a determinadas direções e diferentes campos visuais.

Após o acesso principal, no primeiro ambiente de permanência o usuário se depara com um lance de escada rampeada, que não estranhamento não revela o seu destino. As visuais e as descobertas ocorrem aos poucos. Somente durante este percurso, orquestrado pelo arquiteto, que se pode notar como os ambientes estão conectados por esta circulação funcional e percurso conceitual.

\section{Prada Epicenter (Nova York, 2000-2001)}

Na Prada de Nova York, Koolhaas propõe uma nova abordagem da organização do programa de uma boutique, transformando-a num espaço público, uma galeria ou um espaço para apresentações. Organizado em dois pavimentos, térreo e inferior, o programa abriga ambientes multifuncionais, onde o usuário percorre e interage ativamente com o espaço.

Neste projeto nota-se uma busca pela revisão do programa e do conceito de uma loja tradicional, acrescentando o valor social e público deste espaço. As características singulares de cada espaço, que confere riqueza e o seu diferencial, são as motivações do arquiteto. Segundo Koolhaas, " $e$ se a equação fosse revertida, para que os clientes não fossem mais identificados como consumidores, mas reconhecidos como pesquisadores, estudantes, pacientes, frequentadores de museus? E se a experiência de compra não fosse de empobrecimento, mas de enriquecimento?" 
O Epicentro Prada de Nova York é uma conversão de um espaço no SoHo, anteriormente pertencente ao Museu Guggenheim. Os olhares são direcionados para o denominado Wave, um espaço curvo, esculpido no térreo, abrindo-o para o piso inferior. De um lado, o plano inclinado ondulado possui degraus, que pode ser um ambiente para expor sapatos e acessórios, ou que podem ser usados como uma área de estar; do outro, em frente, localiza-se um palco, que se desdobra do outro lado da "onda". A loja torna-se assim um espaço público e social, versátil, para eventos como desfiles, exibição de filmes, performances e palestras.

Os dois acessos da loja ocorrem em lados opostos, gerando uma conexão ininterrupta entre a Broadway e a Mercer Street, oferecendo assim uma passagem para pedestres por meio da quadra. Nesta ligação há um suporte para um gigante mural artístico, que muda a base regularmente. Este mural define o tema para a exposição que adentra nos espaços da loja, com vídeos em telas de plasma penduradas em trilhos, dispostas entre itens de vestuário, livros empilhados ao lado de sapatos e monitores interativos.

\section{Stedlijck BASE (Amsterdã, 2017)}

Cinco anos após a inauguração da extensão do Museu Stedelijk ocorrida em dezembro de 2017, foi aberta a Stedelijk BASE, uma nova instalação com curadoria e concepção de Rem Koolhaas, Federico Martelli (AMO) e Margriet Schavemaker (Stedelijk). Cerca de 700 peças de obras de arte moderna e contemporânea do acervo permanente do Museu Stedelijk de Amsterdam passaram pelo estudo cuidadoso dos curadores para que, desta maneira, este conhecimento pudesse ser organizado e espacializado.

Na extensão do Museu Stedelijk, a instalação concebida por Rem Koolhaas e Federico Martelli foi organizada a partir de duas lógicas de percurso: uma cronológica (com início em 1880), que segue o perímetro do ambiente; e a outra, organizada no centro do ambiente, por temas - históricos, sociais, autorais e icônicos, espacializados por meio de painéis expositores verticais, que contribuem para definir diferentes caminhos e percursos, com ambientes de permanência e transição, que, deste modo, estabelecem uma metáfora da cidade.

A disposição das obras por temas foi planejada a partir da história de cada obra de arte, oferecendo ao visitante a possibilidade de criar conexões e inter-relações, de modo não habitual, muito diferente da organização linear tradicional do espaço expositivo.

A conexão entre os dois pavimentos da exposição ocorre por meio de escadas rolantes: ele- 
mento de circulação tão presente nas obras de Koolhaas. Um ambiente de transição entre o pavimento inferior e superior insere o visitante num choque de cores e mensagens, e numa imersão em palavras e frases de efeito.

Rem Koolhaas explica o projeto pelo áudio guia do museu, e afirma que "o percurso criado deveria ser uma metáfora da cidade, com espaços de circulação e surpresas, lugares interessantes, extraordinários e alguns nem tanto, normais". A instalação é descrita pelo museu como "an open-ended parcours", e Koolhaas observa a experiência da visita como a de circular pela cidade, com ruas, praças, avenidas, e a possibilidade de encontros inesperados. A intenção foi promover um percurso com fluidez, para o movimento, apropriado ao mundo contemporâneo.

A narrativa não linear, e as múltiplas camadas de possibilidades visuais e informações oferecidas, estão alinhados ao modo de vida contemporâneo das pessoas. O visitante pode criar atalhos e circular livremente pelo espaço a partir do que chamar mais sua atenção, criando conexões e associações com diferentes artes de modo inusitado e inesperado, fazendo com que a curiosidade guie sua visitação.

O percurso proposto rompe com o modo tradicional de circulação em espaço expositivo, quebrando dogmas e oferecendo liberdade na experiência do espaço e na rede de relações possíveis.

A mostra oferece arte em diferentes expressões como pintura, escultura, colagens, arquitetura, mobiliário e design. De um ponto de vista elevado, o visitante é naturalmente convidado a subir um lance de escadas para poder continuar o trajeto e sua apreciação de obras de design. O percurso pela estreita escada conduz ao bal cão superior que tem uma vista cuidadosamente planejada, reveladora e surpreendente, onde o visitante pode observar toda a exposição do BASE e sua organização a partir de um ponto de vista superior.

O sistema expositivo dotado por planos verticais, desenvolvido de modo inovador, e usufruindo a mais alta tecnologia, permite que os visitantes percorram os caminhos livremente e tenham visuais importantes da exposição a partir de cada ponto de localização. Portanto, foram excluídas as salas ou galerias fragmentadas tradicionais que privilegiam, o domínio visual do todo pelo visitante.

Os planos são tão finos como telas, e promovem a fluidez, leveza e flexibilidade pretendida para o espaço. São posicionados em diagonais e ângulos oblíquos entre eles, criando ambientes estreitos e amplos, oferecendo percursos não óbvios aos visitantes, além de visuais e perspectivas convidativas, inusitadas e surpreendentes. O uso do preto e branco também contribui para o dinamismo e contraste entre os planos. 
O visitante pode escolher livremente seu percurso e criar conexões inesperadas entre arte, arquitetura, design, moderno e contemporâneo. Todos os elementos remetem ao movimento e fluidez do espaço, inclusive o desenho do forro e da iluminação. Neste tipo de circulação não óbvia, o visitante é encorajado a optar por diferentes percursos no espaço, para descobrir com liberdade. Portanto, trata-se de diferentes modos de propor percursos e gerar pontos de atração inesperados.

\section{Discussão}

A partir da leitura dos textos do arquiteto, e, sobretudo, por meio de análises dos projetos e visitas aos edifícios, foi possível confirmar o pressuposto inicialmente formulado: Koolhaas cria edifícios dotados de um sistema de circulação que é um híbrido entre o modelo de percurso moderno e o pós-moderno, ou seja, espaços fluidos e contínuos, que oferecem um domínio do espaço pelo único olhar, e o modelo quadro a quadro, de surpresas, descobertas pelos percursos.

Nesta pesquisa foi verificado a relevância dos elementos de circulação para a definição da concepção espacial. Também foi possível observar que os percursos planejados no projeto materializam os conceitos definidos pelo arquiteto. Portanto, há uma importante relação entre programa de necessidades, conceito, partido, e a circulação, percurso e suas visuais.

Se consideramos que "labirinto" se caracteriza por uma "construção onde uma rede de salas e galerias se entrecruzam de tal maneira que fica difícil encontrar a saída", e "dinâmico", "relativo ao movimento, que se modifica continuamente", podemos dizer que a experiência de vivenciar os espaços dos edifícios concebidos por Koolhaas é como um labirinto dinâmico, com visuais inesperadas ao longo do percurso que exige um usuário ativo e atento, como numa metáfora do mundo contemporâneo.

Nos projetos analisados, com caráter cultural, verificamos um programa que requer espaços públicos, acessíveis, e com circulação funcionalmente bem resolvida. A ideia da circulação em "espiral" pode ser observada em diversas ocasiões. Esses problemas de projeto, propostos e solucionados pelo arquiteto, geraram espaços dinâmicos, que exigem do usuário uma participação ativa.

É importante destacar que, ao analisar estes projetos, foi possível verificar que a soluções adotadas respondem à uma inquietude conceitual, muito além das meras questões funcionais. É visível como Koolhaas se apropria do desenvolvimento do projeto para transmitir mensagens e metáforas relacionadas ao mundo contemporâneo. Neste sentido, a definição da circulação, dos percursos, e exploração de visuais contribuem para a materialização destes objetivos, cuja origem é conceitual. 


\section{Considerações finais}

A obra de arquitetos importantes, como é o caso de Rem Koolhaas, é rica de significados e repleta de possibilidades de interpretação. Há muitas lacunas a serem preenchidas por pesquisas futuras, tanto no âmbito da área de projeto de arquitetura, como na área de teoria, história.

Esta pesquisa se restringiu a uma análise focada na circulação de edifícios, com especial atenção na percepção e sensações provocadas pelo espaço. Assim, oferece uma análise interpretativa de edifícios culturais concebidos por Rem Koolhaas, a partir desta abordagem original.

Por meio das análises, é possível afirmar que o sistema de circulação e seus elementos definem e estruturam o partido arquitetônico dos projetos analisados, materializam conceitos, além de corresponder as intenções do próprio arquiteto em seus escritos e declarações.

Agradecimentos

Este artigo teve apoio de pesquisa financiada pelo CNPq, que investiga circulação e percurso pelos espaços em arquitetura. 


\section{Referências}

BENEVOLO, L. A arquitetura do novo milênio. São Paulo: Estação Liberdade, 2007.

CASA da música. Catálogo Casa da Música. Portugal. Porto, 2015.

CAPRINI, A. B.; TACLIARI, A. Estudo da circulação e percurso em quatro edifícios culturais projetados por Paulo Mendes da Rocha para a cidade de São Paulo. Congresso Projetar. Anais ... Curitiba: UFPR, 2019, p.1-13

CECILIA, F. M.; LEVENE, R. C. 1987-1998 OMA/Rem Koolhaas. El croquis 53+79. Madrid: El Croquis Editorial, n. 53/79, 2005 .

GALINDO, V. B. M. Da cidade genérica ao Junkspace. 0 pensamento de Rem Koolhaas sobre a cidade contemporânea. Dissertação (Mestrado em Arquitetura). Natal: UFRN, 2018.

KOOLHAAS, R. Elements. Italy: Marsilio, 2014.

KOOLHAAS, R. Três textos sobre a cidade. Barcelona: Gustavo Gilli, 2010.

KOOLHAAS, R. Rem Koolhaas conversas com Hans Ulrich Obrist. Barcelona: Gustavo Gilli, 2009.

KOOLHAAS, R. Rem Koolhaas conversa com estudantes. Barcelona: Gustavo Gilli, 2002.

KOOLHAAS, R. S,M,X,XL. New York: The Monacelli Press, 1995.

MONEO, R. Theoretical anxiety and design strategies in the work of eight contemporary architects. Cambridge: The MIT Press, 2004

MONTANER, J. M. Sistemas arquitetônicos contemporâneos. Barcelona: Gustavo Gilli, 2009.

PAULA, F. R. F. de. Rem Koolhaas: Trânsitos entre teoria e estratégias projetuais. Dissertação de Mestrado. São Paulo: USJT, 2010.

RAUTERBERG, H. Entrevistas com arquitetos. Munchen, Germany: Prestel Verlag, 2008.

TACLIARI, A. Modelos conceituais de percurso e circulação no projeto de arquitetura. Revista 5\% Arquitetura + Arte, v1, n16, 2018.

TAGLIARI, A; FLORIO, W. O Sistema de Circulação como Estratégia Projetual. Análise do Projeto Espaço Natura de Roberto Loeb. ArqUrb, v. 24, p. 146-166, 2019.

TACLIARI, A.; FLORIO, W. Métodos de análise gráfica. Estudo da circulação, percurso e movimento no projeto de arquitetura. Revista Educação Gráfica, v.23, n2, 2019, p.351-370

TACLIARI, A.; FLORIO, W. Stedelijk BASE. Proposta de um percurso dinâmico para o espaço expositivo. Uma metáfora da cidade por Koolhaas e Martelli. Arquiteturismo,147-4, ano 13, junho 2019.

ZAERA-POLO, A. 1987-1992 OMA/Rem Koolhaas. El croquis 53. Madrid: El Croquis Editorial, n. 53, 1995. 